\title{
Growth of Copper Indium Telluride (Cuinte) Thin Films Using Electrochemical Route for Photovoltaic Application
}

\author{
Subash Adhikari and N.B. Chaure \\ Department of Physics, University of Pune, India \\ e-mail: subashadhikari@hotmail.com
}

\begin{abstract}
Copper indium di-telluride (CuInTe ${ }_{2}$; CIT) was electrochemically deposited onto indium tin oxide (ITO) substrate using aqueous medium at various electrodeposition conditions like temperature, $\mathrm{pH}$, stirring rate and concentration of the samples. The resulting thin films were characterized using UV-Visible-NIR spectrophotometer, X-ray diffractometer, scanning electron microscopy and energy dispersive X-ray to find out energy band gap, structural properties, surface morphology and the elemental composition in the film respectively. The resulting films showed a polycrystalline nature with band gap varying from 1.27 to $1.89 \mathrm{eV}$. The elemental composition of the as deposited and annealed sample showed that the films were mostly copper and tellurium rich. The crystallinity of the films improved after annealing for 5 minutes at $350^{\circ} \mathrm{C}$ but the secondary phase like $\mathrm{Cu}_{\mathrm{x}} \mathrm{Te}$ and $\operatorname{In}_{\mathrm{x}} \mathrm{Te}$ could not be recombined completely.
\end{abstract}

Key words:aqueous medium, $\mathrm{CuInTe}_{2}(\mathrm{CIT})$, deposition potential, electrodeposition, thin films

\section{Introduction}

The growing demand of energy and degrading NonRenewable resources has provoked the search for alternatives. The alternatives have been found as Solar, Wind, Geothermal and Tidal energy which have such a huge potential that if used on a theoretical scale it will exceed the energy demand and will also be supplying till the need remains. Solar Energy is sought as the most prominent alternatives that will drive the world's Energy demand. There are varieties of materials found suitable for the Solar Energy conversion through photovoltaic method but presently most of the interests are concentrated on ternary chalcopyrite IIII-VI semiconductors which can be fabricated into thin film solar cells in low costs using electrochemical method. I-III-VI group elements include Copper-Silver, Germanium-Indium-Aluminum and Tellurium-
Arsenide-Selenium (Shay 1975). Out of these, research on Copper Indium Selenium (CIS) and Copper Indium Gallium Selenium (CIGS) using low cost production techniques like electrodeposition (ED) has proved significantly important. Because of its favorable electrical, optical and semiconducting properties and its feasibility of large scale fabrication, CIS and CIGS based thin films have attracted many research interests (Chen 2009). The utilization of ED method to produce these thin films offers great economic advantage since ED does not require complicated facilities such as vacuum chamber or elevated temperature operation. The energy band gap of about $1.2 \mathrm{eV}$ with high absorption coefficient $\left(\sim 10^{5} \mathrm{~cm}^{-1}\right)$ of CIGS and band gap of $1.1 \mathrm{eV}$ with absorption coefficient of $3 \times 10^{4} \mathrm{~cm}^{-1}$ of CIS make these compounds most suitable for 
photovoltaic application (Muftah 2010, Araujo 2007). The interest towards these photovoltaic devices has further increased by the reported efficiency of $19.9 \%$ of CIGS (Repins 2008) and 11.3\% of CIS Solar Cell (Lincot 2004). However, the efficiency of CIGS seems to saturate (Araujo 2007) and polycrystalline CIS exhibits complex defect chemistry (Pandey 1996). In the electro deposition of films containing copper, indium, gallium, tellurium and selenide from aqueous bath, the components viz. copper, indium and selenium exhibit widely differing electro deposition potentials thus the growth of stoichiometric CIS and CIGS films has not been possible (Kumar 2008). Also the high selenium vapor pressure at elevated temperature has caused excessive selenium losses during annealing. This research thus focuses on tellurium based compound to make highly efficient and cost effective Copper Indium Telluride (CIT) Solar Cells.

CIT is a direct band gap semiconductor for which a variation of band gap within $0.92-1.04 \mathrm{eV}$ was reported for bulk material (Marin 1998). CIT has a greater advantage as the band gap value is very close to the optimum value for the solar energy conversion and it can be prepared as both p-type and n-type semiconductor (Elsoud 1993). Hence researches are concentrated on Tellurium based compound to make high efficient and cost effective Solar cells.

This article describes the preparation of CIT films using aqueous electrodeposition method along with various characterization techniques implied to investigate the physical and chemical structure of the elements in the films.

\section{Methodology \\ Preparation of CIT films}

The project was aimed to develop a cost effective technique so electro deposition in aqueous medium was employed to produce CIT films. The sample was prepared in $100 \mathrm{ml}$ distilled water with $1 \mathrm{mM}$ of Cupric Sulphate, $4 \mathrm{mM}$ of Indium Sulphate and $1 \mathrm{mM}$ of Tellurium oxide. Similarly $2 \mathrm{mM}$ of citric acid was added in the solution as complexing agent to increase the solubility of the Tellurium (Oda \& Murare 2001). The electro deposition was carried out with Indium Tin Oxide (ITO) as a working electrode and Graphite as a counter electrode. External power for the deposition was supplied through 0-15 volts variable power supply and the external heat was supplied through $2 \mathrm{MLH}$ heater with magnetic stirrer to stir the solution.
In order to find the optimum parameters for the deposition of stoichiometric CIT film, different sets of films were deposited under different conditions. The final optimum parameters thus obtained indicated that $\mathrm{pH}$ of the sample had to be within the range of 1.8-1.9, external potential to be of the range -1.4 to -1.9 volts, stirring rate to be normal (300-400 rpm), bath temperature $90-95^{\circ} \mathrm{C}$ and annealing conditions has to be maximum 5 minutes exposure at $350^{\circ} \mathrm{C}$ in air. Similarly to investigate the variation of stoichiometry and composition of films the original 1:4:1 concentration of cupric sulphate, indium sulphate and tellurium oxide was changed to 1:8:1 and 1:4:4 keeping all other parameters fixed.

\section{Characterization of the CIT films}

Optical properties of the film like band gap and absorption characteristics of the film were studied through JASCO UV-VISIBLE-NIR Spectrophotometer (V-670). The spectroscopy was carried out under the range of 200-1400nm. The structural properties were studied from the D8 X-Ray Diffractometer with CuKá radiation (1.54 $\AA$ ) at an operating voltage of $40 \mathrm{KV}$ and $40 \mathrm{~mA}$ current. The samples were evaluated under range of 20-60 Degree with the increment (grazing angle) as $0.80^{\circ}$. The results obtained were compared with JCPDS database to find different elements present. The surface and near surface regions were studied using JOEL Scanning Electron Microscope (SEM). Similarly the elemental compositions in the film were analyzed using JOEL (JED 2300) Energy Dispersive X-Ray analysis (EDAX).

\section{Results and Discussion}

The band gap of as deposited films at -1.4 Volts and annealed at different temperatures having 1:4:4 and 1:4:1 concentration is shown in fig. 1 . The band gap of the as deposited sample with 1:4:1 concentration was found to be increasing with the higher negative potential. With a least band gap of $1.27 \mathrm{eV}$ at -1.4 volts the band gap value increased maximum up to $1.61 \mathrm{eV}$ at -1.9 volts. The intermediate films had a varying band gap. Similarly the sample with 1:4:4 concentrations had band gap varying from $1.53 \mathrm{eV}$ at -1.4 volts to $1.63 \mathrm{eV}$ at -1.9 volts. The annealed $1: 4: 1$ sample at $400^{\circ} \mathrm{C}$ showed the band gap varying from 1.41 to $2.02 \mathrm{eV}$. The higher band gap was seen in almost all the films, same as the as deposited ones. Similarly the 1:4:4 annealed samples had band gap of $1.89 \mathrm{eV}$ to $1.82 \mathrm{eV}$ at the potential of -1.4 and $-1.9 \mathrm{eV}$. 


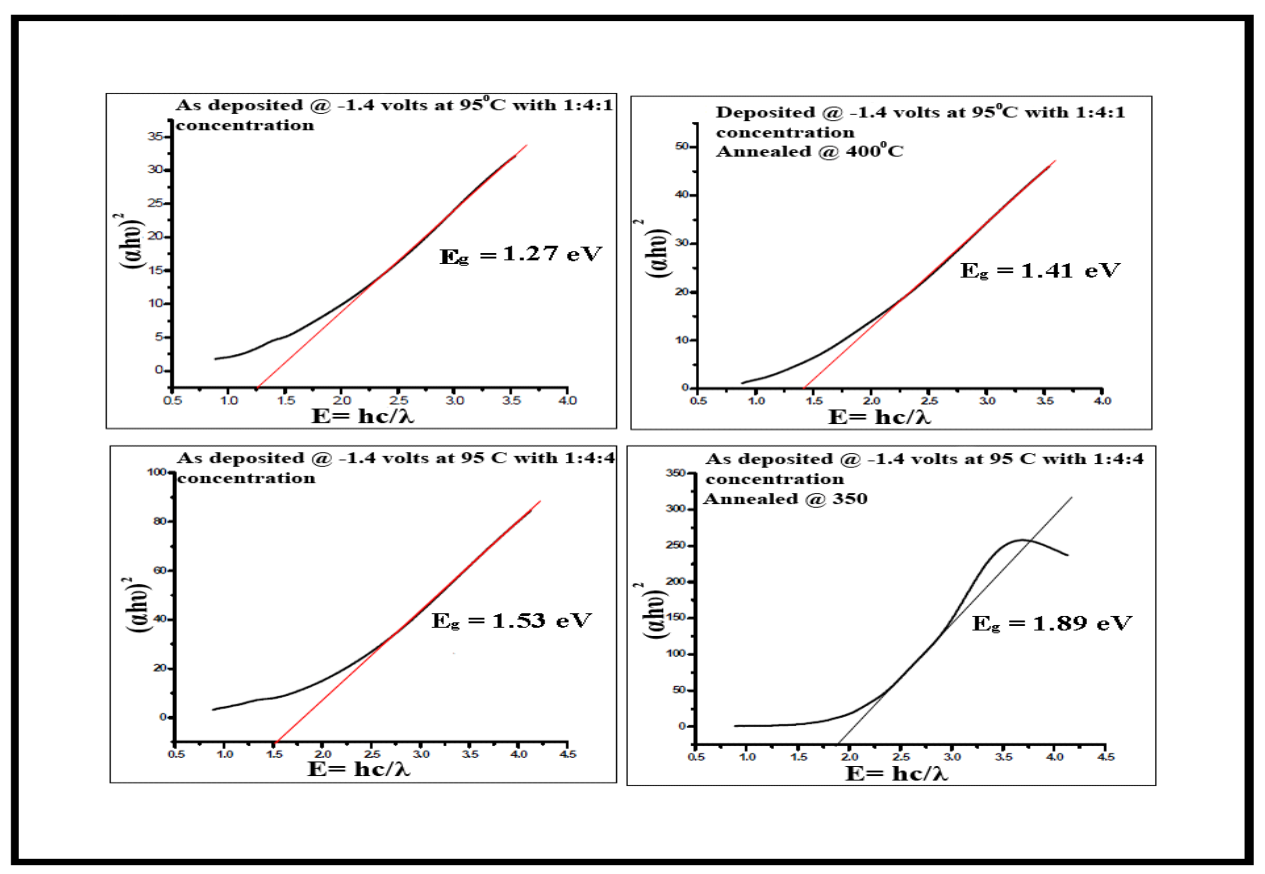

Fig. 1. as deposited and annealed films at different concentration

Fig. 2 shows the X-Ray Diffraction peaks of as deposited and annealed samples at -1.5 Volts at two different concentrations of 1:4:4 and 1:4:1. Analysis of as deposited films showed the presence of polycrystalline CIT Peaks at 2 è $~ 24.70(<112>$ ) along with $\mathrm{Cu}_{\mathrm{x}} \mathrm{Te}$ and $\mathrm{In}_{\mathrm{x}} \mathrm{Te}$ peaks in all the samples. The sample having composition $1: 4: 1$ annealed at $400^{\circ} \mathrm{C}$ and deposited at -1.5 volts showed the presence of
CIT Peaks along with intense peaks of Copper Oxide $\left(\mathrm{Cu}_{2} \mathrm{O}\right)$ and $\mathrm{In}_{4} \mathrm{Te}_{3}$. The annealed 1:4:4 samples at the annealing temperature $350^{\circ} \mathrm{C}$ deposited at potential of -1.5 volts showed the previously observed CIT peaks which were much intense after annealing. The previously observed $\mathrm{In}_{4} \mathrm{Te}_{3}$ peaks were still present in the annealed sample.

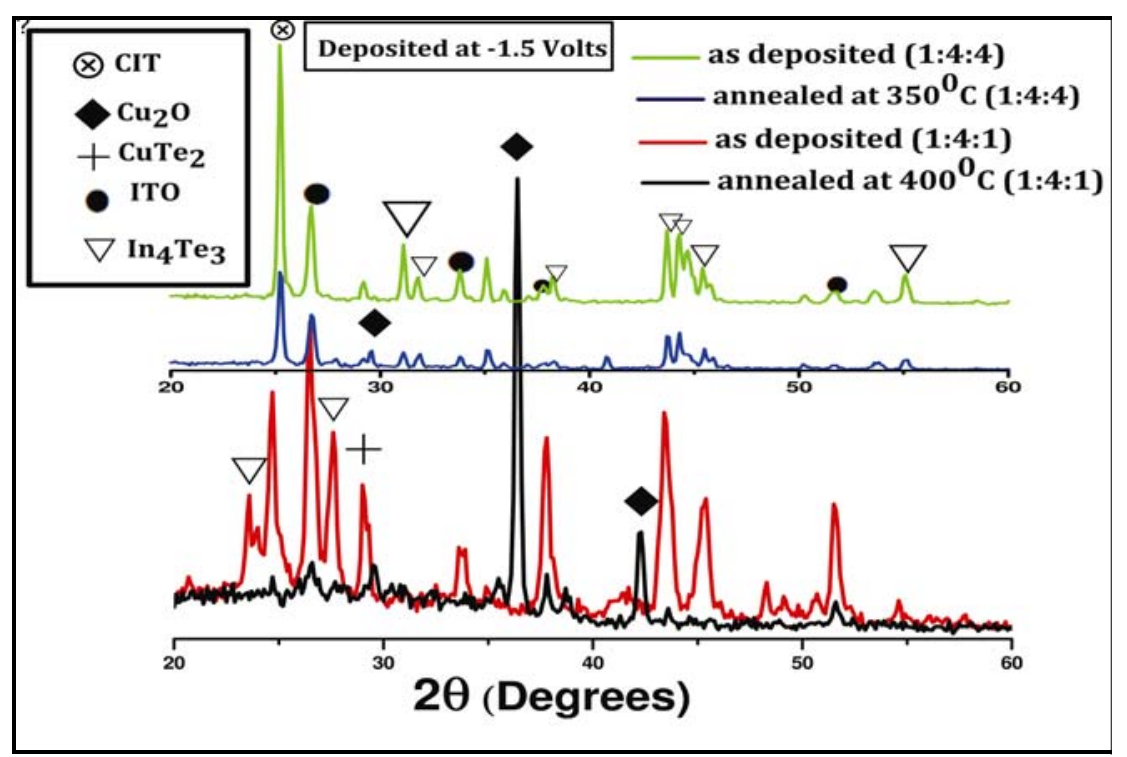

Fig. 2. X-ray diffraction pattern of the films at various concentrations and annealing temperature 
Fig. 3 shows the as deposited and annealed CIT films deposited at -1.4 volts with 1:4:1 concentration. The as deposited films were compact, very well adhesive to the substrate and black grayish in color. Here no separate grain could be observed. The same film was

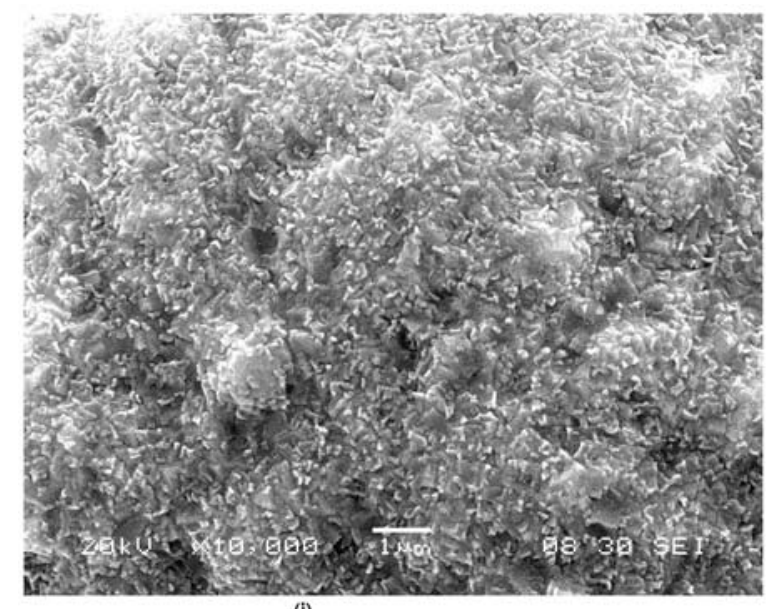

(i) annealed at $400^{\circ} \mathrm{C}$ for 10 minutes. Here the grain size had increased but not uniformly. Smaller grains of size approximately 100nm agglomerated to form the cluster of size over 5ìm. Some grains are of size approximately1ìm.

Fig. 3. (i) as deposited sample at -1.4 volts and (ii) annealed sample at $400^{\circ} \mathrm{C}$ for 10 minutes.

Similarly the element compositions in the film were analyzed using Energy Dispersive X-Ray analysis (EDAX). Fig. 4 shows the EDX result of films deposited at -1.5 volts with concentration of $1: 4: 4$ and $1: 4: 1$

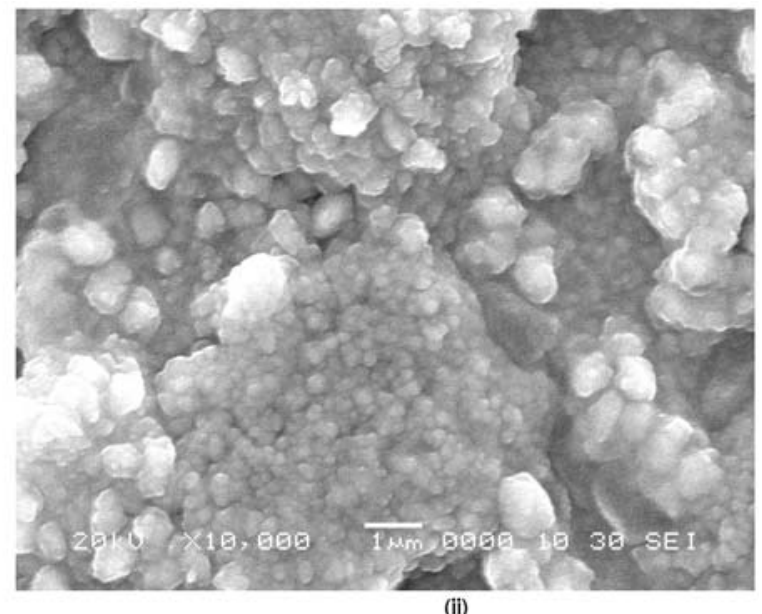

(ii)

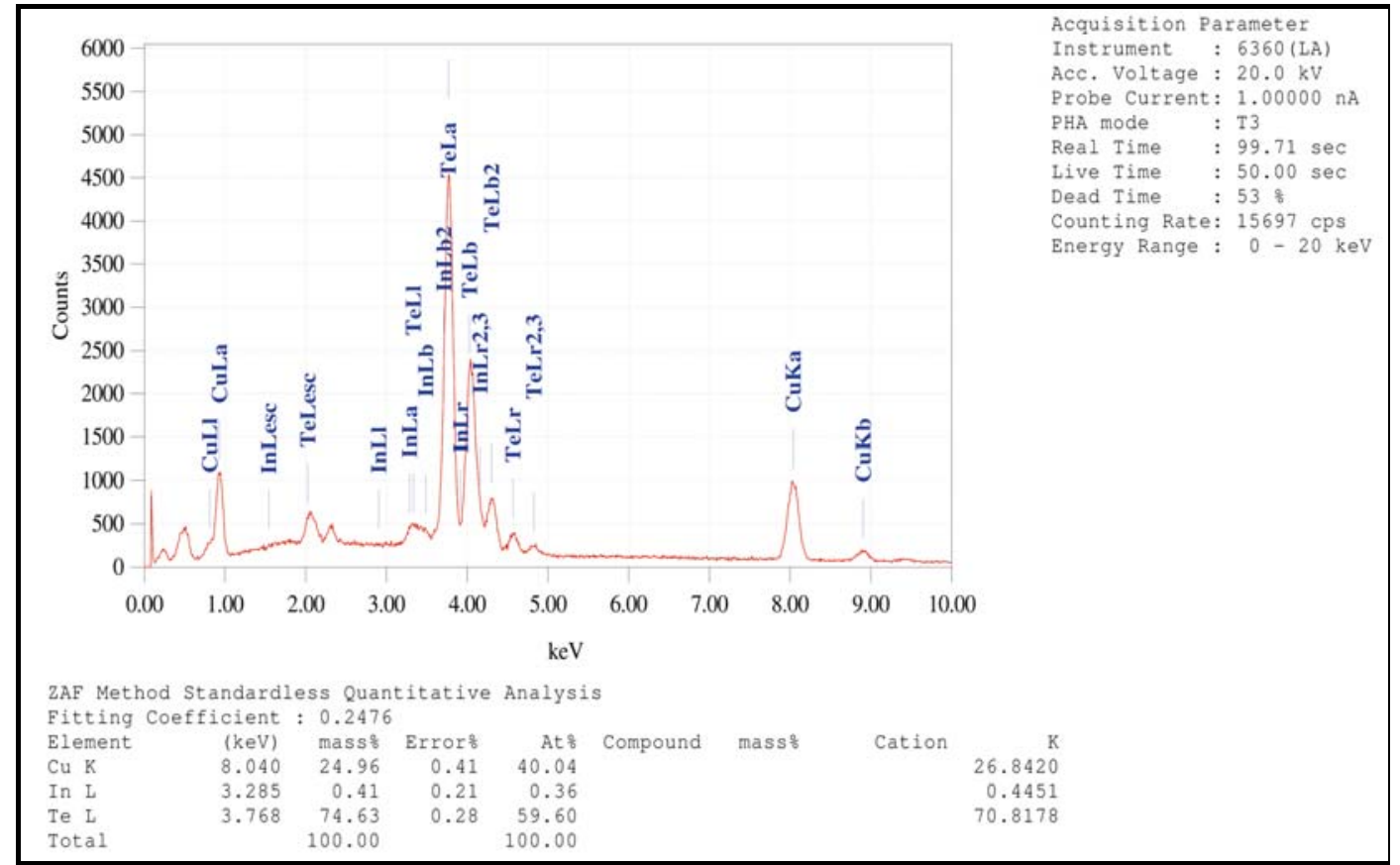

Fig. 4. as deposited film at -1.5 volts with 1:4:1 concentration 
Subash Adhikari \& N.B. Chaure/Growth of Copper Indium ......

Table 1. Elemental composition of films deposited at -1.5 volts at different concentration and annealing condition.

Analysis at -1.5 Volts

\begin{tabular}{|l|l|l|l|}
\hline \multirow{2}{*}{ Elements } & \multicolumn{3}{|c}{$\begin{array}{c}\text { Amount Of Elements on the films Under different concentration and } \\
\text { annealing temperature (amounts in atomic \%) }\end{array}$} \\
\cline { 2 - 4 } & $\begin{array}{l}\text { As Deposited with } \\
1: 4: 1 \text { concentration }\end{array}$ & $\begin{array}{l}\text { Annealed at } 400{ }^{\circ} \mathrm{C} \text { with } \\
1: 4: 1 \text { concentration }\end{array}$ & $\begin{array}{l}\text { Annealed at } 350^{\circ} \mathrm{C} \text { with } \\
1: 4: 4 \text { concentration }\end{array}$ \\
\hline $\mathrm{Cu}$ & 40.04 & 67.51 & 52.45 \\
\hline $\mathrm{In}$ & 0.36 & 0.18 & - \\
\hline $\mathrm{Te}$ & 59.60 & 5.39 & 43.73 \\
\hline $\mathrm{O}$ & - & 1.79 & - \\
\hline $\mathrm{Sn}$ & - & 25.12 & 3.82 \\
\hline
\end{tabular}

The standard band gap of the stoichiometric CIT at room temperature is $0.95 \mathrm{eV}$ (Wasim 1988) so the band gap obtained from the results in Fig. 1 showed a higher band gap than those of CIT suggesting the presence of other compounds of Copper and Indium along with CIT. The increase in the band gap after annealing were due to the evaporation of the dark black CIT films observed in the as deposited sample and formation of compounds of metals like copper and indium which were verified from the X-ray Diffraction result in Fig. (2). The results obtained from the X-ray Diffraction analysis confirmed the presence of CIT peaks which was the objective of the experiment. Similarly, the presence of $\mathrm{Cu}_{\mathrm{x}}$ Te and $\mathrm{In}_{\mathrm{x}}$ Te peaks in Fig. 2. suggests that the compounds were formed because of ease of reduction of the metallic elements at the experimental conditions (Kaufmann 2003). The amount of Indium in the films was very less compared with Copper and Tellurium which suggests the potential during electro deposition was mostly favorable for copper and tellurium rather then Indium. Similarly, the higher band gap of the samples was due to $\mathrm{Cu}_{\mathrm{x}}$ Te present in the film. The results obtained in the heat treated samples can be similarly explained. Less amount of Indium in as deposited films and evaporation of Tellurium during the heat treatment suggest that indium deposition potential and proper annealing conditions were not achieved. The presence of $\mathrm{Cu}_{2} \mathrm{O}$ can be explained on the basis of large amount of oxygen that was found in the film. Since heat treatment was done in open air, the oxygen being highly reactive with metals like Copper at high temperature might have formed the oxide of Copper.
The experiment has demonstrated that it is possible to grow polycrystalline CIT films through aqueous electro deposition method at a deposition potential of -1.4 to -1.9 volts and at bath temperature of 80 to $95^{\circ} \mathrm{C}$. Similarly the deposition of films at a stirring rate of 300-400 rpm produces uniform films while at higher rates the as deposited films will peel off from the surface. The $\mathrm{pH}$ value of the solution was also analyzed to be of the range 1.8 to 1.9 and the concentration providing the polycrystalline CIT films were found to be of the ratio of 1:4:4 and 1:4:1. The project completed achieved a polycrystalline CIT material together with phases like $\mathrm{Cu}_{\mathrm{x}} \mathrm{Te}$ and $\mathrm{In}$ Te which were present even after annealing the films. Since the films were copper and tellurium rich and concentration of indium was less, it suggests that indium deposition potential was not achieved and had to be reconsidered. Also improving the annealing conditions can recombine the tertiary phases to produce a crystalline CIT film.

\section{Acknowledgements}

We acknowledge the support of the head, Department of Physics, University of Pune for making necessary arrangements for the experimentation and providing different laboratory facilities.

\section{References}

Shay, J. L., and J. H. Wernick. 1975. Ternary Chalcopyrite Semiconductors: Growth, Electronic Properties and Applications, Oxford, New York, Pergamon Press, U.S.A., 39 pp 
Nepal Journal of Science and Technology 12 (2011) 318-323

Chen, Hue-Hsin, Peter N. Kalu and Egwu E. Kalu. 2009. $\mathrm{CuInSe}_{2}$ thin-film deposition on flexible plastic substrate: electrolyte recirculation rate and deposition potential effects. J. Solid State Electrochemistry 14:1013-1020

Huang, CJ, TH Meen, MY Lai, WR Chen. 2004. Formation of CuInSe2 thin films on

flexible substrates by electrodeposition (ED) technique. $J$. Sol Energy Mater Sol Cells 82:553-565

Muftah, G. E. A., A.P. Samantilleke, P.D. Warren, S.N. Heavens and I. M. Dharmadasa. 2010. Electrochemical Deposition of CuInTe $\mathrm{C}_{2}$ Layers for Applications in thin Film Solar Cells. J. Mater Sci: Mater Electron 21:373-379

Araujo, J., R Ortiz, Rivera A Lopez, JM Ortega, M. Montilla, D. Alarcon. 2007. Electrochemical growth of $\mathrm{CuInSe}_{2}$ thin film on different substrates from alkaline medium. Characterization of the films. J. Solid State Electrochem 11:407-412

Repins, I, M A. Contreras, B. Egaas, De Hart C, J. Scharf, C L Perkins, B To and R Noufi. 2008. Characterization of 19.9\%-Efficient CIGS Absorbers. In: Proceedings of 33rd IEEE Photovoltaic Specialists Conference,San Diego, California (May 11-16, 2008) 16: 235-239

Lincot, D., J.F. Guillemoles, S. Taunier, D. Guimard, J. Sicx-Kurdi, A. Chaumont, O. Roussel, O. Ramdani, C. Hubert, J.P. Fauvarque, N. Bodereau, L. Parissi, P. Panheleux, P. Fanouillere, N. Naghavi, P.P. Grand, M.
Benfarah, P. Mogensen, O. Kerrec. 2004. Chalcopyrite thin film solar cells by electrodeposition. J. Solar Energy 77:725-737

Pandey, R. K, S. N. Sahun, S. Chandra. 1996. Handbook of Semiconductor Electrodeposition, New York Marsall Dekker publisher, 189 pp

Kumar, S.R., B. Prajapati, S.K. Tiwari and V.K. Tiwari 2008. Growth and characterization of Copper Indium and Copper-Indium alloy film using non-aqueous method of deposition. J. Pure and Applied Physics 46: 198-203

Marin, G., S.M. Wasim, G. Sanchez Perez, P. Bocaranda and A.E. Mora. 1998. Crystal growth, structural, and optical characterization of the ordered defect compound $\mathrm{CuGa}_{5} \mathrm{Se}_{8}$. J. Electron. Mater., 27:1351-1357

Elsoud, A.M.A., TA Hendia, LI Soliman, HA Zayed, and MA Kenawy. 1993. Electrodeposition of CuInTe ${ }_{2}$ film from an acidic solution. J. Mater. Sci. 28:1182-1188.

Oda, T., K. Murase, T. Hirato and Y. Awakura. Electrodeposition of ZnTe films with high current efficiency at low overpotential from a citric acid bath. In: The $104^{\text {th }}$ lecture convention proceedings, (26 Sept 2001),Japan chapter 6, pp.146.

Wasim, S.M. and J.G. Albornoz. 1988. Electrical and Optical Properties of n- and p-Type CuInTe $e_{2}$. Phys. Status Solidi A 110: 575-583

Kaufmann, L. Elton. 2003. Characterization of Materials, Wiley publishers $789 \mathrm{pp}$. 